\title{
DESIGN OF AN EXPERIMENTAL WORKBENCH FOR FORCE CONTROL TESTS WITH PNEUMATIC ACTUATORS
}

\author{
Roberta Goergen \\ Department Exact Sciences and \\ Engineering \\ UNIJUÍ \\ Panambi, RS, Brazil
}

\author{
Marcia Regina Maboni Hoppen \\ Porsch \\ Department Exact Sciences and \\ Engineering \\ UNIJUÍ \\ Panambi, RS, Brazil
}

\author{
Marianna Gioppo de Souza \\ Department Exact Sciences and \\ Engineering \\ UNIJUÍ \\ Panambi, RS, Brazil
}

\author{
Luiz Antônio Rasia \\ Department Exact Sciences \\ and Engineering \\ UNIJUÍ \\ Panambi, RS, Brazil
}

\author{
Antonio Carlos Valdiero \\ Department Exact Sciences and \\ Engineering \\ UNIJUÍ \\ Panambi, RS, Brazil
}

\begin{abstract}
The need of the use of mechatronic systems and manipulator robots performing tasks of precision and repetitiveness in the most diverse areas of industry, agriculture and services, require in some situations the contact between the manipulator and the environment, in the desired and programmed movements for the execution of robotized work. These situations, of contact of the mechanism and / or final effector with the environment, are characterized in a problem of force control. Pneumatic actuators are used for interaction between the robot and the environment, due to controllable stiffness. It is perceived that due to the compressibility of the air, it is more advantageous and safer in applications involving the risk of accidents and the need to limit the forces of interaction with the environment. The main objective of this paper is to show the design of an experimental workbench for position control and force control for pneumatic actuators. The used methodology is based on phases that can be named as Need Analysis, Conceptual Design, Preliminary Design, Detail Design, Prototype Construction, Test and Evaluation; and Final Documentation. The experimental prototype is being developed and tested at the Innovation Center for Automatic Machines and Servo Systems (NIMASS) in UNIJUÍ University (Brazil), which has adequate computational and experimental infrastructure for the construction of a bench of tests to verify and to validate the performance of the modeling and control of force on pneumatic actuators. It is concluded that the developed workbench can contribute to the study of the modeling and design of pneumatic systems applications in machines. Theoretical and experimental knowledge enhances the development of innovations and the transfer of technology to the productive sector.
\end{abstract}

Keywords: control force, pneumatic actuators, experimental workbench

\section{INTRODUCTION}

This work addresses the design of an experimental workbench for position control and force control for pneumatic actuators. In robotics, the force control is one of the most studied topics, where it is used to describe the interaction between a robot and an unknown environment with applications in the industry, agriculture, medicine and services. $[1,2,3,4]$

Currently, in a large number of robotic systems, the need for a natural interaction with the environment requires the actuator to be treated as a source of actuation force, i.e., a force generator. As such, the capability of precisely modulating the output force in the presence of external disturbance makes a significant research topic in the robotic application of pneumatic actuators. [5, 6]

Today pneumatic actuators are widely used to perform various industries motion tasks. They have the advantages of low purchase price and robust design, but show high energy consumption in comparison with electric drives. Existing energy saving measures lead to the reduction of energy consumption, but at the same time they cause the increase of the life cycle costs. All in all, the selection of pneumatic drives has been done regarding their functionality, efficiency and costs. [6, 7]

Friction is an important phenomenon in many mechanically driven systems. The friction force Fatri has a highly non-linear behaviour. Friction is a multifaceted non-linear phenomenon that exhibits many non-linear characteristics. They are composed by well-known and classic static friction (stiction), Coulumb friction, viscous friction and drag 
friction, that compose the simpler models based in static maps. Otherwise, they are composed by more complex dynamic phenomena known as Stribeck friction, rising static friction, frictional memory and presliding displacement. It is important to emphasize that, in general the friction characteristics are dependent of velocity, temperature, movement direction, lubrication and the wear between contact surfaces, and even position and movement history. [8, 9]

\section{METHODOLOGY}

In order to increase the probability of success of new pneumatically driven robotic workbench with force control, the design process was planned carefully and executed systematically. In particular, an engineering design method must integrate the many different aspects of designing in such a way that the process becomes logical and comprehensible. To that end, the design process of robotic system must be broken down, first into phases and then into distinct steps, each with its own working methods. It is with these aims in mind that several authors split the design process into main phases that can be named as Need Analysis, Conceptual Design, Preliminary Design, Detail Design, Prototype Construction, Test and Evaluation; and Final Documentation of Robot Drives and Mechanism as shown in Figure 1. [10, 11]

Design Process of Robotic Systems

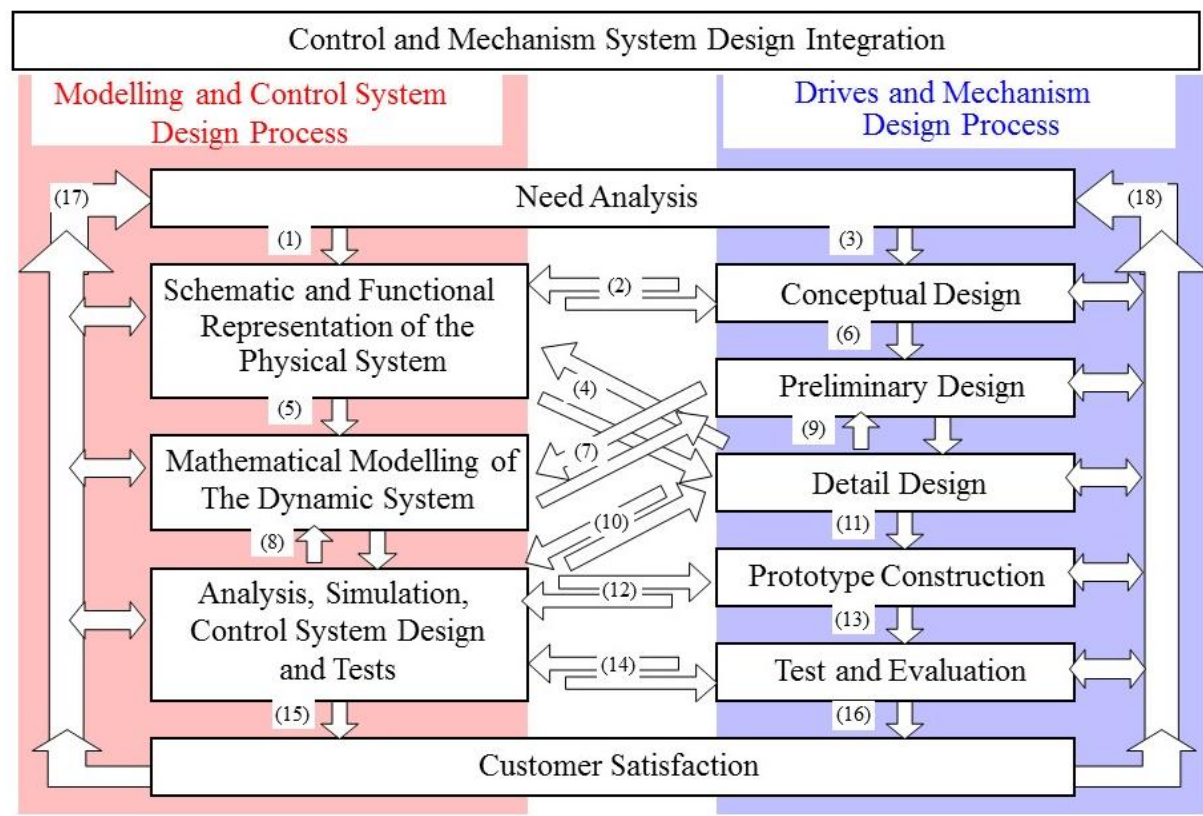

Figure 1 - Design Methodology of smart machines and robots (adapted from [10])

According to [10], from the Needs Analysis phase, the modelling and controller design methodology can be divided into the three main phases and illustrated in Figure 1: schematic and functional representation of the physical system; mathematical modelling; and analysis, simulation, controller design and tests.

\section{RESULTS}

This section presents the results of the design and construction of an experimental workbench for position control and force control for pneumatic actuators and experimental tests used to identify some parameters in pneumatic actuators. All programs were implemented on MATLAB.

\section{Design and Construction of Experimental Workbench}

The 2 illustrates the detailed design and construction of an experimental workbench for force control tests with pneumatic actuators that is being developed and tested at the Innovation Center for Automatic Machines and Servo Systems (NIMASS) in UNIJUÍ University (Brazil). The laboratory has adequate computational and experimental infrastructure for the construction of a bench of tests to verify and to validate the performance of the modeling and control of force on pneumatic actuators. 


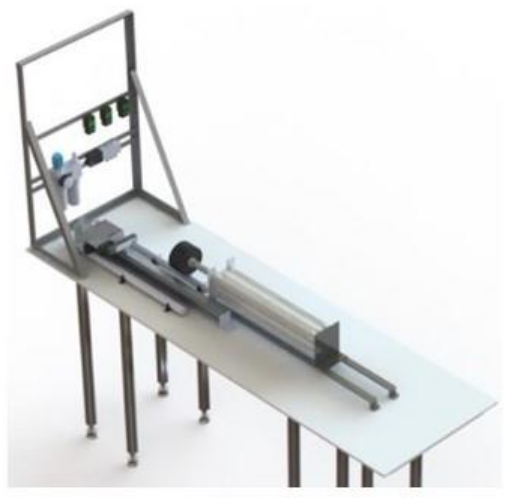

(a)

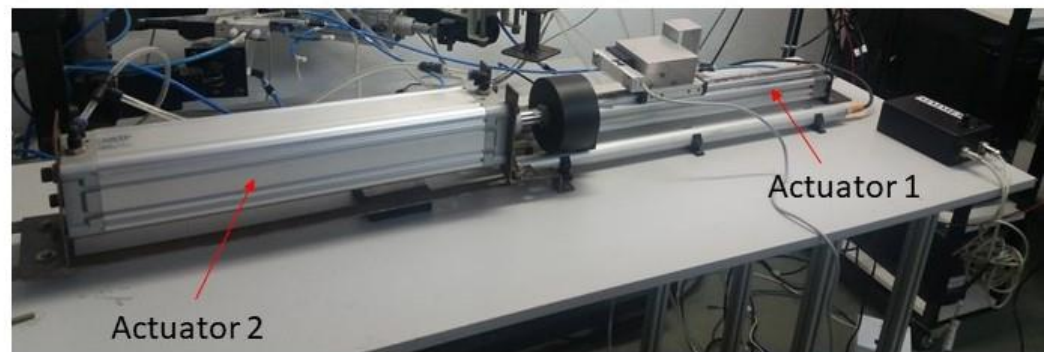

(b)

Figure 2 - Design of an experimental workbench for force control (a) Design in CAD model; (b) Photograph of experimental prototype

The developed workbench study contributed to the modeling and design of pneumatic systems applications.

\section{Simulated and Experimental Results}

The Figure 3 shows static map of the actuator 1 and Figure 4 presents static map of the actuator 2. The graphics were obtain through many experiments carried out with velocity values being changed from around null velocity to maximum system value. These experiments were fulfilled with test apparatus configured as an open loop system, when a constant pneumatic valve opening possibilities that pneumatic actuator moves with constant velocity.

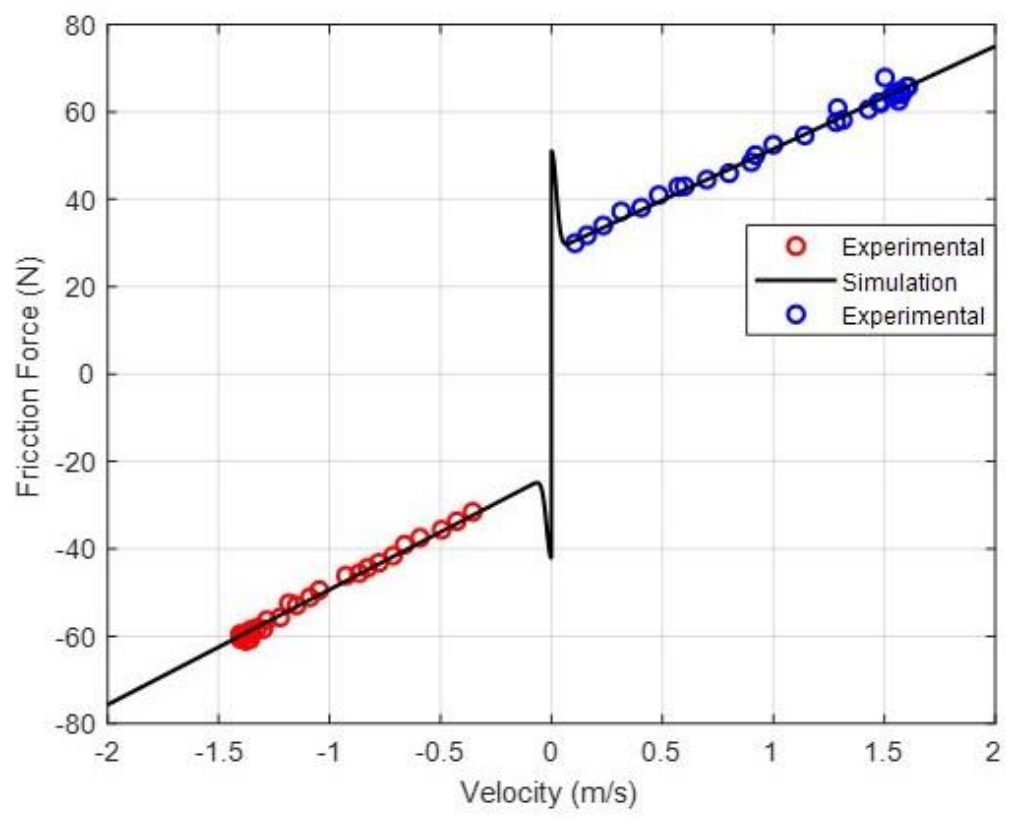

Figure 3 - Static friction-velocity map in steady state to pneumatic actuator with experimental values to actuator 1 


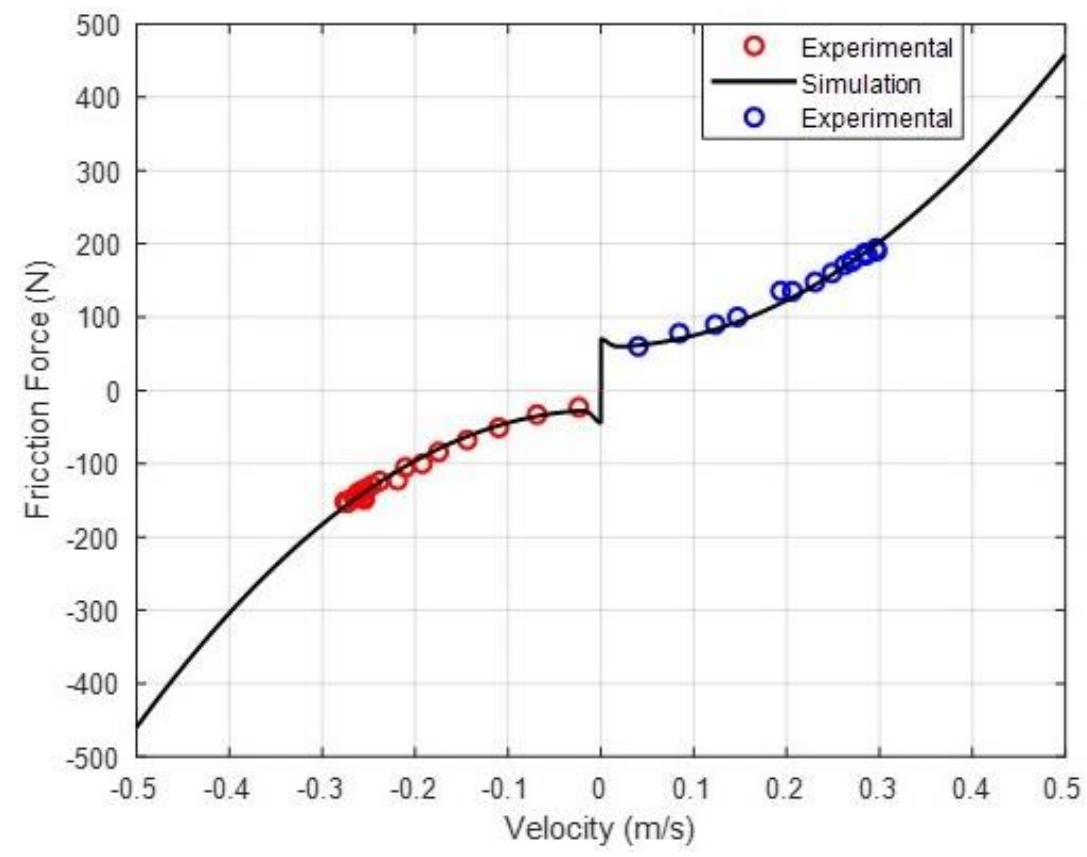

Figure 4 - Static friction-velocity map in steady state to pneumatic actuator with experimental values to actuator 2

The identification of steady state friction $\left(F_{a t r i, s s}\right)$ is important because we can consider at constant speed that the result of the forces in the pneumatic actuator is

$$
f_{L i}=F_{p i}-F_{a t r i, s s}
$$

Where $F_{p i}$ is pneumatic force to each pneumatic actuator and $f_{L i}$ is load force.

Figure 5 gives the comparison of the results in open-loop between the pneumatic force simulation and the load force in actuator 1. According to Equation (1) the force control is useful with friction compensation of the pneumatically driven robotic workbench.

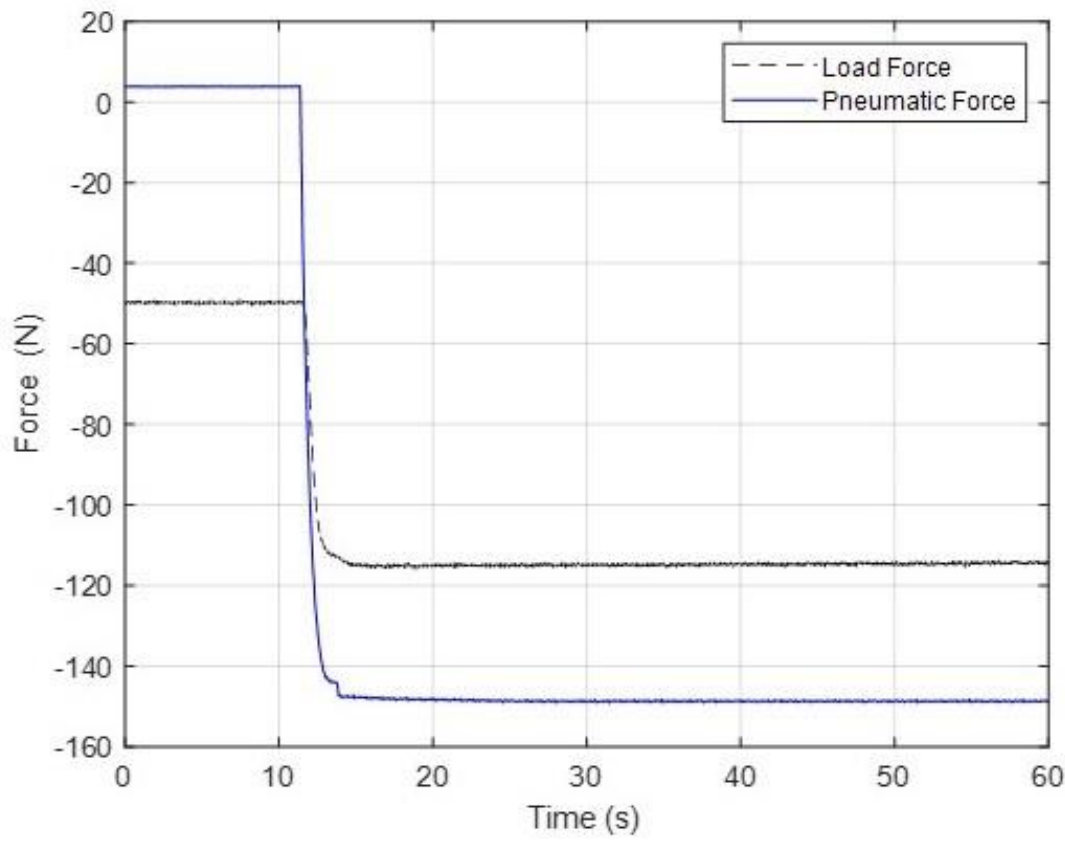

Figure 5 - Results of open-loop dynamics of Load Force and Pneumatic Force in Actuator 1 
From Figure 6, it can be seen that the results of force feedback control in actuator 1 . In this experiment the actuator 2 was stopped, thus simulating the environment.

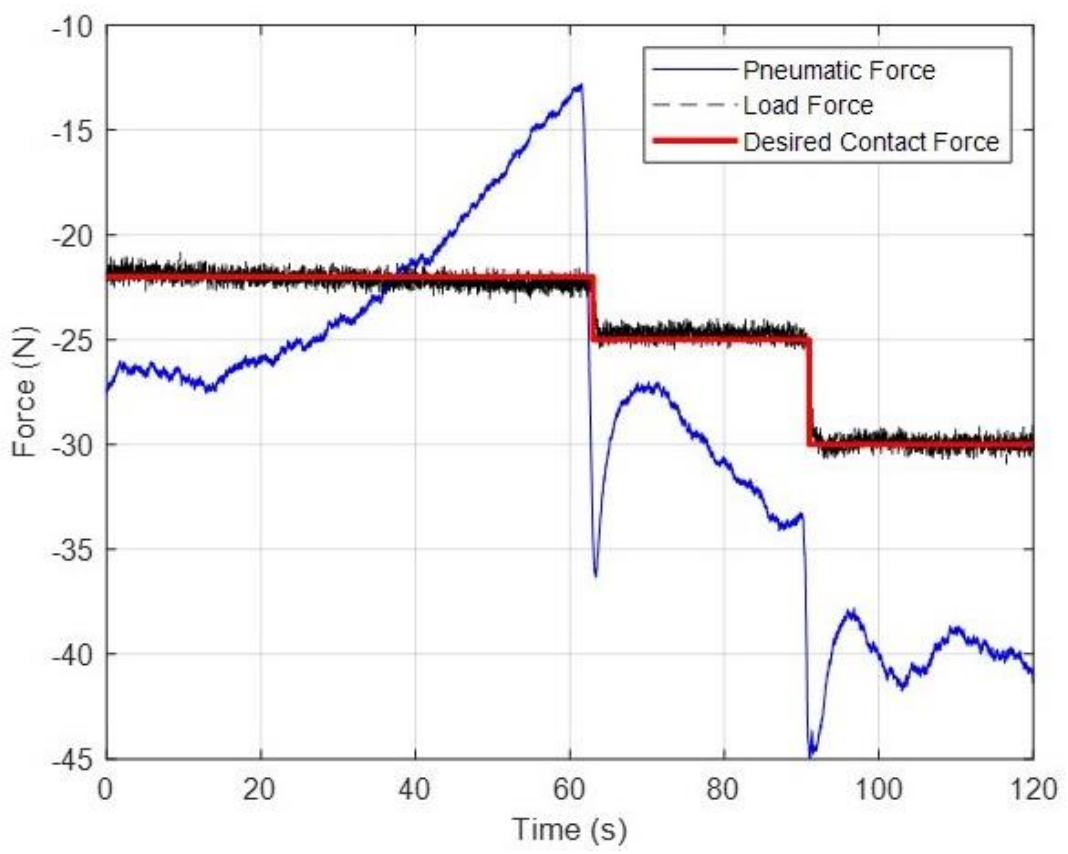

Figure 6 - Results of Force Feedback Control in Actuator 1

In this experimental workbench was also made the calibration of the load cell. The results were obtain experimentally for the calibration of the load cell and the adjusted curve.

\section{CONCLUSION}

This work presented a detailed prototype of an experimental workbench for position control and force control for pneumatic actuators. In addition, friction dynamics were experimentally identified in pneumatic actuators, which exhibit nonlinear behavior at low speeds. These results will be used for the benefit of the prototype with respect to determination of parameters, validation of the robot's mathematical model and control strategies.

\section{ACKNOWLEDGMENTS}

This study was financed in part by the Coordenação de Aperfeiçoamento de Pessoal de Nível Superior - Brasil (CAPES) - Finance Code 001. This work has financial support from Fapergs (project number 17/2551-0001014-0, Edictal 02/2017). The authors also would like to thank CNPq, FINEP, UNIJUÍ and IFFAR.

\section{REFERENCES}

[1] Li, R., Meng, G., Feng, Z., Li, Y., Shi, W. A sliding mode variable structure control approach for a pneumatic force servo system. In Intelligent Control and Automation. WCICA 2006. The Sixth World Congress on (Vol. 2, pp. 81738177). IEEE, 2006

[2] Li, X., Liu, Y. H., Yu, H. Iterative learning impedance control for rehabilitation robots driven by series elastic actuators. Automatica, 90, pp 1-7, 2018.

[3] Dong, W., Guan, R., Yuan, L., Gu, X., Anwar, A., Lin, W. Adaptive impedance based force and position control for pneumatic compliant system. In Industrial Electronics Society, IECON 2017-43rd Annual Conference of the IEEE (pp. 2949-2954). IEEE, Oct. 2017.

[4] Sellier, A., Brun, X., Sesmat, S., Retif, J. M., Lin-Shi, X., Thomasset, D., Smaoui, M. Hybrid force control with on/off electropneumatic standard distributors. International Journal of Fluid Power, 7(1), pp 51-60, 2006 
[5] Ben-Dov, D., Salcudean, S. E. A force controlled pneumatic actuator, IEEE Transactions on Robotics and Automation, Vol 11, Issue 6, pp 906-911, 1995

[6] Driver, T., Shen, X. Pressure estimation-based robust force control of pneumatic actuators. International Journal of Fluid Power, 14(1), pp 37-45, 2013.

[7] Rakova, E., Weber, J. Exonomy Analysis for the Selection of the Most Cost-Effective Pneumatic Drive Solution. In 9th FPNI Ph. D. Symposium on Fluid Power. American Society of Mechanical Engineers, Oct. 2016

[8] Valdiero, A. C. Modelagem matemática de robôs hidráulicos. Ijuí: Unijuí, 2012

[9] Goergen, R., Porsch, M. R. M. H., Valdiero, A. C., Rasia, L. A., Oberdörfer, M., Souza, J. P. de, Gonçalves, R. S. Design of a Pneumatically Driven Robotic Workbench for Rehabilitation. International Journal of Development Research Vol. 08, pp. 22408-22413, Aug. 2018

[10] Valdiero, A. C., Rasia, L. A. Gestão de projetos de pesquisa e desenvolvimento de produtos mecatrônicos. In: Desafios em engenharia industrial. Ijuí: Unijuí, pp. 89-106, 2016

[11] Valdiero, A. C., Ziech, R. O., Pinto, M. S., Mantovani, I. J.,Rasia, L. A. Development and Construction of an Instrumentalized Workbench With a Hydraulic Motor for Farm Machine Testing. In 9th FPNI Ph. D. Symposium on Fluid Power. American Society of Mechanical Engineers, Oct. 2016 